\title{
Full-Scale Branch Campuses in China
}

\author{
DAVID A. STANFIELD and WANG QI
}

David A. Stanfield is a research assistant at the Boston College Center for International Higher Education and doctoral student in Boston College's Higher Education Administration program. E-mail: david.stanfield@bc.edu. Wang Qi is an assistant professor at the Graduate School of Education, Shanghai Jiao Tong University, China. E-mail: qimwang@sjtu.edu.cn.

Two full-scale British branch campuses currently operate in mainland China, and two prominent American institutions will soon open. With intentions to replicate the world-class education offered on their home campuses, these foreign outposts have generated considerable attention. China poses a variety of unique challenges that may hinder branch campuses from achieving this aim.

\section{Characteristics of Full-Scale BRanch CAMPUSES}

International branch campuses in China are unique, due to the Ministry of Education's stipulation that foreign institutions must form a legal partnership with a local Chinese university. Although approximately 20 international branch campuses exist in China, a majority are small niche institutions, offering one or two degree programs with small enrollments. In contrast, 4 branch campuses seek to offer a range of disciplines at the undergraduate and postgraduate levels that reflect the quality and experience of their home institutions. The University 
of Nottingham Ningbo China (UNN), the first full-scale branch campus in China, currently enrolls over 5,000 students and cooperates with the nonprofit Zhejiang Wanli Education Group. Xi'an Jiaotong-Liverpool University (XJTLU), with over 3,200 students, collaborates with Laureate, a prominent American for-profit education group. With campuses already well under construction, two notable American institutions-Duke Kunshan University (partnered with Wuhan University) and New York University (NYU) Shanghai (partnered with East China Normal University) — are slated to open full-scale operations in the near future.

Full-scale international branch campuses are established as independent entities and adopt the foreign partner's curriculum and organizational structure, although the Ministry of Education requires some modification in order to receive accreditation. For instance, institutions must offer a course on Chinese culture and abide by national admission guidelines. The liberal education offered by Western institutions is a new and welcome addition in a system that has struggled to cultivate critical thinking, innovation, and entrepreneurship. These international branch campuses also plan to engage in research production, by leveraging the strength of local university partners.

\section{Future Potential: World-Class EdUCATION?}

In The Challenge of Establishing World-Class Universities, Jamil Salmi proposes that world-class universities exhibit a concentration of talent, an abundance of resources, and appropriate governance. This is a useful framework to examine the potential for full-scale branch campuses in China to reproduce the educational experience of their home campuses. 
Talent. World-class institutions require highly qualified students and faculty. Branch campuses rely on similar admissions standards to their home campuses, including college essays, high school transcripts, and in-person interviews; and in China, the national entrance exam (Gaokao) is also required. This array of admissions requirements will help branch campuses identify qualified applicants and maintain high standards; however, whether or not a sufficient number of qualified students will apply is uncertain. The ability of institutions to recruit top-tier applicants in their home countries cannot be assumed by the branches in China. The elite Chinese universities easily recruit top students, due to the perceived value of their degrees in the local job market. Furthermore, in a society that relies on personal networks, students believe toptier public institutions will help build the relationships necessary to receive the highest paying and most sought after jobs. Despite the international prestige and recognition of the Western branch campus brands, students hoping to work in China will likely prefer a degree from an elite public university. Moreover, even though foreign outposts clearly state that degree requirements and course offerings mirror the home institution, students often perceive branches as inferior.

World-class universities also require highly qualified faculty and researchers. XJTLU and UNN recruit full-time, long-term faculty from their home campuses and internationally. Though, in practice, international branch campuses often struggle to recruit home-campus faculty-due to inflexible research and teaching obligations, the hassle of moving abroad, and incompatibilities with tenure and promotion systems. To attract top faculty, branch campuses must offer and highlight generous salary packages, 
supplemental research funds, and other nontangible benefits-such as the opportunity to work in a dynamic growing economy. One promising report indicated several professors and researchers from UNN, and XJTLU received competitive Chinese research grants.

Resources. Although full details are not available, financial models for branch campuses in China seem to be a mix of support from the local or provincial government, the Chinese university partner, private industry, and student tuition fees with less financial investment from the home campus. NYU Shanghai is rumored to have negotiated a range of financial support, requiring no investment from the home campus in New York City; whereas, the Duke Kunshan reports contributing several million dollars to the startup and planning expenses.

Tuition fees range broadly from 60,000 RMB to 132,500 RMB (US\$9,500 to US\$20,800) at UNN, XJTLU, and NYU Shanghai. UNN and XJTLU's fees are lower than in the United Kingdom, while NYU and the Duke Kunshan will reportedly charge similar tuition to the home campuses, in New York and North Carolina, and offer some financial aid and scholarships. When compared to the tuition fees of top-tier public universities, between 5,000 RMB and 6,000 RMB (US\$750 and US\$950), parents and high school graduates will think twice before considering branch campuses. However, branch campuses are a reasonably priced alternative, compared to the increased cost of studying abroad. Yet, an increasing number of Chinese families can afford to send their children overseas and, when given a choice, most will prefer the full experience of studying abroad. 
Additional revenue sources such as intellectual property, corporate partnerships, and private donations from alumni and foundations are in their infancy in China and will take time to cultivate. Developing world-class education and research is expensive, and the ability of international branch campuses to secure adequate funding will be a significant challenge.

Governance. Western-style higher education relies on governance structures that promote autonomy, academic freedom, and free inquirystandards that differ and may conflict with Chinese requirements and local partner expectations. For instance, the Ministry of Education requires that branch-campus presidents be Chinese nationals, who may not fully grasp Western education ideals and leadership styles. Moreover, despite the promise of autonomy on curricular matters, recent governmental concerns over quality assurance could lead to additional regulation. Perhaps most vital to the Western institutions, academic freedom cannot be guaranteed-due to local laws and cultural sensitivities. Legal arrangements and other outside pressures may prevent international branch campuses from creating the governance models necessary to reach world-class status.

\section{CONCLUSION}

Full-scale branch campuses in China hope to situate themselves in the top-tier of Chinese higher education institutions by providing Western-style education, attracting highly qualified students and faculty, and engaging in research production. While the Chinese system affords some potential advantages, numerous challenges will make the road to educational excellence an arduous journey. 